\title{
Tutupan Terumbu Karang di Pulau Lirang Kabupaten Maluku Barat Daya
}

\author{
Kurnia Adi Nusaputro*, Sri Redjeki, Endang Sri Susilo \\ Departemen IImu Kelautan, Fakultas Perikanan dan Ilmu Kelautan, Universitas Diponegoro \\ JI. Prof. H. Soedarto S.H, Tembalang,Semarang, Jawa Tengah 50275 Indonesia \\ ${ }^{*}$ Corresponding author, e-mail: adi.nusaputra@gmail.com
}

\begin{abstract}
ABSTRAK : Penelitian mengenai persentase tutupan substrat pada perairan terumbu karang ini dilakukan di Pulau Lirang Kabupaten Maluku Barat Daya. Penelitian yang dilakukan di perairan Pulau Lirang bertujuan untuk mengetahui persentase tutupan substrat di perairan tersebut. Pengumpulan data dilakukan bulan April 2016 pada enam lokasi dengan transek sepanjang 100 meter. Data dihimpun dengan menggunakan metode Point Intersept Transect (PIT) menggunakan peralatan SCUBA. Hasil penelitian menunjukkan rerata tutupan karang hidup di Pulau Lirang, Maluku Barat Daya adalah 33,75\%, dengan tutupan tertinggi pada stasiun VI (54\%). Kematian karang yang mencapai $48 \%$ di stasiun $\mathrm{V}$ diduga disebabkan oleh persaingan dengan soft coral atau biota bentik lainnya, arus dan sedimentasi. Dominasi karang Acropora, foliose dan massive di perairan Pulau Lirang dapat diartikan masih terjadinya kesetimbangan ekosistem terumbu karang di perairan tersebut, dimana Acropora sebagai indikator percepatan pertumbuhan dan pemulihan, karang foliose menandakan ketahanan akan kerusakan fisik seperti arus dan gelombang dan karang massive sebagai indikator ketahanan perubahan iklim global.
\end{abstract}

Kata Kunci : Tutupan substrat, tutupan karang, bentuk pertumbuhan, Maluku Barat Daya

\section{Coral Reef Cover on Lirang Island, Southwest Maluku Regency}

ABSTRACT : Research on the percentage of substrate cover on coral reef waters was conducted in Lirang island, Southwest Maluku Regency. The aim of this research was to determine the percentage of substrate cover in the waters. Data collection was conducted in April 2016, in six locations with $100 \mathrm{~m}$ long transect for each location. The data was collected using Point Intercept Transect (PIT) method using SCUBA equipment. The result showed that average live coral cover in Lirang Island waters, Southwest Maluku is 33,75\%, with the highest coral cover at Station VI (54\%). The exsisting coral mortality at Station $V(48 \%)$ was assumed because of competition with soft corals or other benthic biota, and sedimentation. The domination of the coral life form Acropora, Foliose, and Massive in Lirang island waters indicated that the ecosystem balance in these area was still maintained. The existence of Acropora life form is an indicator of accelerated growth and recovery, while foliose life form is an indicator of durability and physical damage from current and wave. Lastly, massive coral life form is an indicator of resistance to climate change.

Keywords: Substrate cover, coral cover, life form, Southwest Maluku

\section{PENDAHULUAN}

Terumbu karang (Coral Reef) merupakan salah satu ekosistem yang unik serta sebagai tempat pemijahan ikan (spawning ground), penyedia makanan bagi biota laut (feeding ground) dan sebagai daerah pembesaran (nursery ground). Terumbu karang memiliki nilai ekologi, ekonomi dan estetika yang tinggi (Zamani, 2006; Nontji, 2007; FAO, 2000).

Terumbu karang yang ditemukan di Indonesia diperkirakan sebanyak 590 spesies, yang termasuk ke dalam 80 genus. Terumbu karang di Indonesia cukup memprihatinkan dari \pm 85.707 $\mathrm{Km}^{2}$ luas areal terumbu karang di Indonesia berkategori $(6,20 \%)$ sangat baik, $(23,72 \%)$ baik, $(28,30 \%)$ sedang dan $(41,78 \%)$ buruk atau rusak (Arini, 2013; Suharsono, 2008).

Kondisi terumbu karang dipengaruhi oleh aktifitas manusia seperti adanya polusi atau limbah industri, pembuangan sampah rumah tangga, aktifitas pariwisata serta disebabkan oleh faktor alamiah seperti pemanasan global dan sedimentasi (Tomascik et al., 1997; Annas et al., 2017). 
Ekosistem terumbu karang di Kabupaten Maluku Barat Daya dapat dikatakan masih baik. Survei yang telah dilakukan oleh Estradivari et al. (2016) mencatat 57 genus karang keras dan 403 spesies ikan karang ditemukan dalam transek. Substrat dasar didominasi oleh karang keras $(37,2 \%)$ dan karang lunak $(26,8 \%)$. Sebagian besar karang keras $(89,1 \%)$ di Kabupaten Maluku Barat Daya kondisinya sehat. Meski saat ini kondisinya masih baik, tekanan terhadap ekosistem terumbu karang terjadi di seluruh Kabupaten. Degradasi ekosistem pesisir telah terjadi dalam 10 tahun belakangan dan berdampak pada penurunan jumlah dan ukuran biota, khususnya biota target perikanan.

Pulau Lirang yang berada di Kabupaten Maluku Barat Daya, merupakan salah satu laut Indonesia yang kaya akan sumber daya alam perairan terutama ekosistem terumbu karang. Informasi mengenai ekosistem terumbu karang khususnya wilayah perairan Pulau Lirang masih sangat terbatas. Penelitian ini dilakukan untuk mengetahui persentase tutupan substrat pada perairan terumbu karang yang ada di Pulau Lirang, Maluku Barat Daya.

\section{MATERI DAN METODE}

Pengambilan data dilakukan pada kedalaman 1-3 meter pada keseluruhan stasiun yang disesuaikan dengan kondisi perairan. Peralatan yang digunakan adalah alat selam (SCUBA), alat tulis bawah air dan meteran tali (roll meter).

Pengamatan terumbu karang menggunakan Metode Transek Titik Menyinggung (Point Intersept Transect - PIT). Metode ini digunakan untuk mengukur tutupan karang, avertebrata bentik sesil, alga dan tipe substrat. Metode ini dapat memperkirakan kondisi terumbu karang di daerah berdasarkan persen tutupan karang batu hidup dengan mudah dan cepat. Secara teknis, metode Point Intercept Transect (PIT) adalah cara menghitung persen tutupan (\% cover) substrat dasar secara acak (Hill dan Wilkinson, 2004).

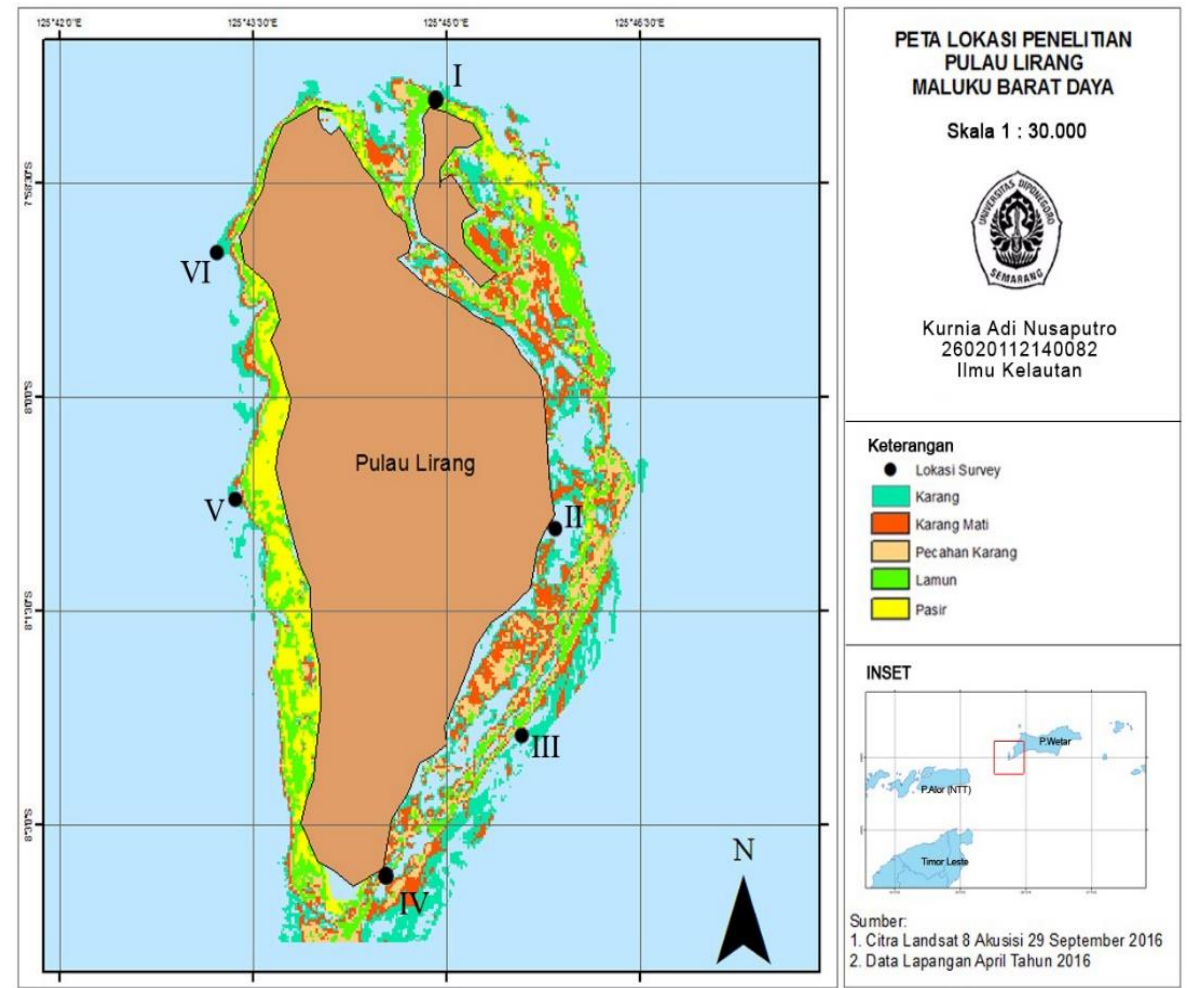

Gambar 1. Peta Lokasi Penelitian

Pengamatan dengan menggunakan metode PIT yang tersaji pada gambar 2 yaitu dengan cara pengamat berenang di transek sepanjang $100 \mathrm{~m}$ dan mencatat kategori bentuk hidup seperti Hard Coral Life (HCL), karang lunak, avertebrata bentik sesil, algae, biota lainnya, substrat 
bergerak dan substrat yang tersedia yang berada tepat dibawah pita berskala (roll meter) dengan interval 0,5 meter di sepanjang transek yang dimulai pada titik $0,5 \mathrm{~m}$ dan berakhir pada $50 \mathrm{~m} \mathrm{(100}$ titik per pita = total 200 titik) (Ahmadia et al., 2013).

Analisis data menggunakan program Microsoft Excel dan dibuat grafik maupun tabel. Menghitung persentase tutupan substrat terumbu karang menggunakan rumus English et al (1994).

\section{HASIL DAN PEMBAHASAN}

Terumbu karang di stasiun I didominasi oleh karang keras (scleractinian) dengan tutupan sebesar $36 \%$, Sand $25 \%$ dan Rubble 14\%. Karang keras merupakan penyusun terumbu utama dari ekosistem terumbu karang, karena karang keras memiliki laju kalsifikasi sebesar $75 \mu \mathrm{mmol}$ $\mathrm{CaCO}_{3} \mathrm{~m}^{-2}$ hari ${ }^{-1}$ (Langdon et al, 2000). Tutupan halimeda pada stasiun I ini cukup kecil yakni hanya sebesar $1 \%$. Halimeda dikatakan juga sebagai penyusun (produser) dari terumbu karang yang memiliki thalus dan kalsium karbonat. Halimeda tidak seperti alga lain yang memilisi selulosa di dalam sel thalusnya (Hillis-Colinvaux, 1980).

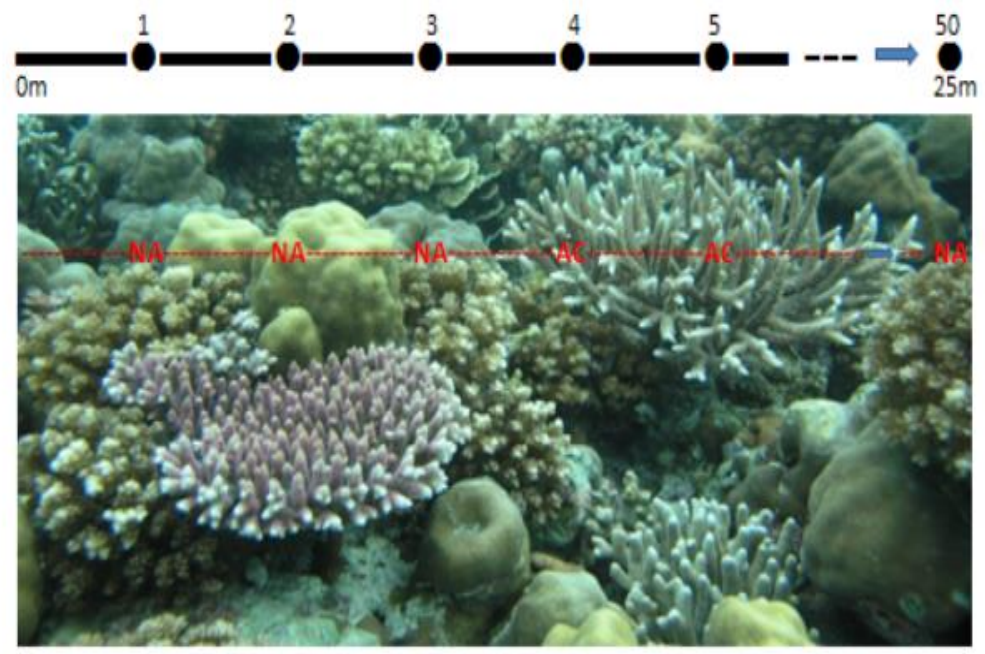

Gambar 2. Point Intercept Transect (Ahmadia et al., 2013)

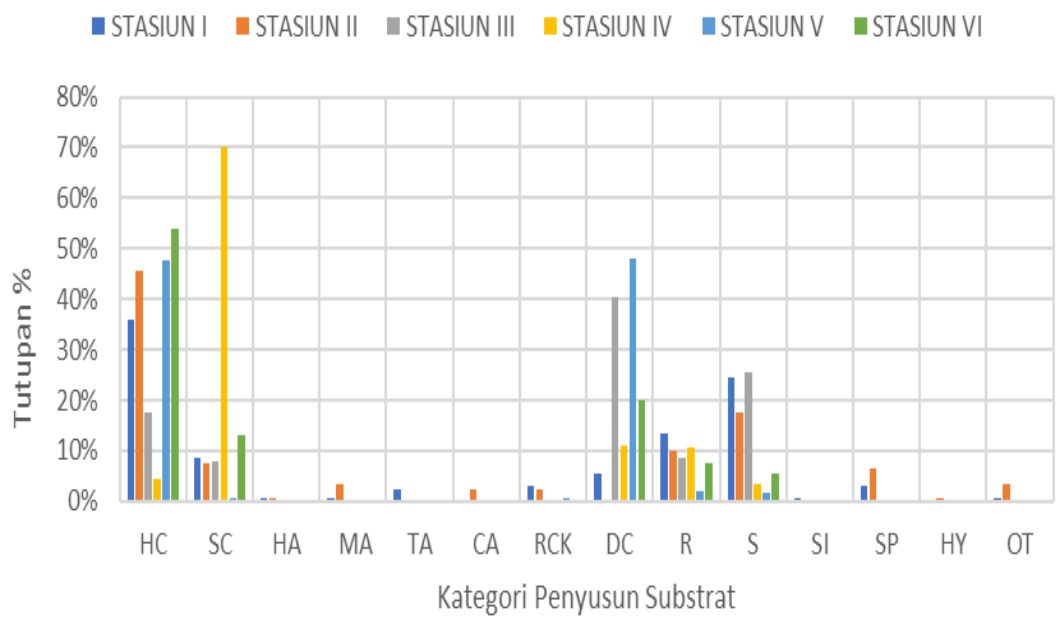

Gambar 3. Persentase tutupan substrat di perairan Pulau Lirang dari semua stasiun penelitian

Selain tersusun atas pembentuk terumbu karang, terumbu karang di stasiun I ini juga terdiri dari turf algae 3\% dan macro algae 1\%. Alga adalah salah satu kompetitor dari karang keras, Smith, et al (2006), mengatakan alga akan mengeluarkan zat kimia tertentu yang akan membuat 
karang keras akan mengalami kematian, bahkan jenis alga tertentu akan menularkan mikroba tertentu bagi karang sehingga akan terjadi penyakit pada karang keras. Kasus di lapangan turf alga (alga yang tingginya $2-5 \mathrm{~cm}$ ) berkompetisi ruang secara langsung, biasanya turf alga ini akan tumbuh dari bawah dan kemudian akan menyerang karang hidup dengan cara menempelinya dari bawah hingga keatas, karang yang tidak memiliki sistem pertahanan yang baik akan mengalami kematian. Lingkungan abiotik di stasiun I ini didominasi oleh pasir putih $25 \%$ dan pecahan karang/ rubble sebesar $14 \%$. Rubble bisa berasal dari rock yang memiliki tutupan $3 \%$ atau karang yang sudah mati (DC) dengan tutupan 6\% (Gambar 3). Karang yang telah mati atau rock apabila terpecah secara alami karena gelombang dan arus dari laut akan membentuk fragmen yang lebih kecil apabila berukuran 1-10 cm disebut dengan rubble dan apabila berukuran 0,5-1 cm disebut sebagai pasir (sand) dimana di Pulau Lirang tutupan pasir cukup tinggi yakni $25 \%$. Penyebab terjadinya rubble dapat bermacam-macam seperti adanya event badai, ombak yang besar (agitation wave), gempa bumi, bio erosi, akibat pendaratan kapal dan bom ikan (Rasser and Riegl, 2002). Silt atau lumpur dan pasir (sand) merupakan ancaman bagi kesehatan karang, partikel dari keduanya berpotensi menutup polip karang sehingga akan mengganggu proses mencari makan (up take) pada karang. Pasir dan lumpur ketika tersapu arus akan memperkecil visibilitas perairan dan menahan penetrasi cahaya kedalam laut sehingga akan mengurangi proses fotosintesis simbion dari karang. Peningkatan pasir dan sediment perairan juga merupakan pemicu bagi meledaknya alga pada substrat dasar perairan, sehingga akan mengurangi kesuksesan penempelan juvenile karang pada substrat (Birrell et al, 2005).

Stasiun II tepat berada di tanjung kecil, memiliki tutupan karang cukup tinggi yakni $46 \%$ mungkin bisa dikaitkan juga dengan keberadaan coralline alga (3\%) yang hanya ditemukan pada stasiun ini. Coralline alga atau disebut juga crustose coralline algae (CCA) memiliki peran yang sangat penting pada ekosistem terumbu karang seperti sebagai kerangka bagi organisme bentik, melekatkan fragmen berkarbonat pada terumbu, penyedia sinyal kimia tertentu bagi larva atau juvenil karang agar menempel pada substrat dan sebagai salah satu produsen utama karbonat pada sedimen (Kuffner, et al. 2008). Soft coral memiliki tutupan sebesar $8 \%$ di stasiun II, biasanya ditemukan bergerombol di dekat pecahan karang (rubble). Karang keras dan karang lunak (soft coral) saling berkompetisi untuk mendapatkan ruang, bahkan soft coral yang memiliki zat kimia tertentu akan menimbulkan kematian pada karang keras apabila kontak langsung dengannya (Sammarco, et al. 1983). Kondisi abiotik di stasiun II mirip dengan stasiun I, yakni didominasi oleh rubble (10\%) dan pasir (18\%) (Gambar 3). Pada daerah pantai stasiun II ini tidak ditemukan ekosistem mangrove, sehingga berdasarkan gambar 3 hampir tidak ditemukan lumpur pada sekitar ekosistem terumbu karang. Lumpur (silt) adalah bersifat terrigenous atau berasal dari pelapukan dan proses erosi pada daratan yang terbawa air hujan atau aliran sungai dan akan mengendap pada dasar perairan laut.

Persentase tutupan karang keras di di stasiun III adalah sebesar $18 \%$, soft coral $8 \%$ sedangkan tutupan substrat abiotik cukup tinggi untuk dead coral $41 \%$, rubble $9 \%$ dan pasir $26 \%$ (Gambar 3). Jenis substrat biotik dan abiotik di stasiun III ini hanya berjumlah 5 jenis merupakan paling sedikit dibandingkan dengan stasiun lainnya. Banyaknya karang mati yang ditemukan pada stasiun III ini dimungkinkan dikarenakan sedimentasi, di mana pada pada lokasi ini lamun yang merupakan filter sedimen ke dua dari daratan tidak begitu banyak, sehingga sedimen dari area mangrove akan terus masuk ke perairan yang akan mengganggu proses fotosintesis alga simbion yang berada di dalam jaringan endodermis karang. Selain sedimen, arus yang sangat kencang pada stasiun ini juga diduga berperan mencegah proses settlement juvenile karang ke substrat sehingga tutupan karang di stasiun ini cukup rendah.

Stasiun IV berada sekitar $400 \mathrm{~m}$ dari stasiun III, memiliki karakteristik lingkungan yang hampir sama, yakni berarus deras. Soft coral sangat mendominasi di perairan ini, hampir $70 \%$ tutupan soft coral ditemukan (Gambar 3). berkebalikan dengan soft coral keberadaan hard coral di stasiun ini hanya $5 \%$ yang berarti sangat rendah. Karang keras merupakan pembangun utama dari terumbu dan menjadi habitat bagi hampir semua organisme di terumbu. Soft coral di beberapa tempat di dunia memiliki kemampuan mendominasi substrat perairan seperti yang terjadi di Sesoko Jepang dan di Pulau Iwotorishima, Jepang telah terjadi phase shift dari hard coral ke soft coral (Loya, et al. 2001; Inoue, et al. 2013). Soft coral memiliki kemampuan allopathy yakni mengeluarkan zat kimia (allelochemicals) yang akan membunuh kompetitor, sehingga dengan 
mudah soft coral akan bereproduksi, tumbuh dan bertahan di tempat baru dan mengkolonisasi serta mendominasi dasar perairan (Sammarco, et al. 1983)

Stasiun V yang terletak dibarat Pulau Lirang memiliki tutupan karang keras sebesar $48 \%$ dan tutupan karang mati sebesar $48 \%$ (Gambar 3 ). Wilayah perairan yang tenang akan mempengaruhi kelimpahan karang pada suatu perairan. Connell (1997) mengatakan coral abundance sangat dipengaruhi faktor fisik dari lingkungan seperti kedalaman, paparan gelombang, terekspose udara ketika surut terendah, kecepatan arus dan nutrien.

Tutupan karang pada stasiun VI merupakan tertinggi dibandingkan dengan stasiun yang lain, yakni sebesar $54 \%$. Komponen biotik lainnya yang ditemukan adalah soft coral sebanyak $13 \%$ (Gambar 3). Lingkungan yang sama dengan stasiun $\mathrm{V}$ diduga juga sebagai penyebab tingginya tutupan karang di perairan ini. Kematian karang sebanyak $20 \%$ adalah bukti adanya gangguan juga di perairan tersebut. Secara alami kematian karang bisa disebabkan banyak hal diantaranya adalah kompetisi dengan biota lain seperti alga, sponge maupun soft coral.

Gambar 4 menunjukkan komposisi hard coral berdasarkan life form karang. Ada dua jenis bentuk pertumbuhan dari karang Acropora yaitu Acropora bercabang (Acropora Branching/ ACB) dan Acropora tabulate (ACT). Acropora branching (ACB) ditemukan di semua stasiun penelitian dengan jumlah koloni tertinggi sebesar 66 ditemukan di stasiun $\mathrm{V}$ dan terbanyak kedua berasal dari stasiun VI sebanyak 38 koloni. ACT ditemukan hanya di empat stasiun yakni stasiun I, II, V dan VI. Jumlah terbanyak koloni ACT ditemukan pada stasiun V sebanyak 16 koloni. Ada 5 bentuk pertumbuhan karang non-Acropora yaitu Hard Coral Branching (CB), Hard Coral Encrusting (CE),

Hard Coral Foliose (CF), Hard Coral Massive (CM) dan Hard Coral Submassive (CS). Koloni karang dengan bentuk pertumbuhan CF tertinggi ditemukan pada stasiun VI dengan jumlah 48. Untuk bentuk pertumbuhan CM tertinggi ditemukan pada stasiun II dengan jumlah koloni sebanyak 39 koloni (stasiun II). CM kedua terbanyak ditemukan pada stasiun I dengan 26 koloni. Ciri khas karang diperairan Indonesia adalah mendominasinya karang Acropora hampir di semua perairan dengan berbagai bentuk pertumbuhan seperti, branching, tabulate atau encrusting.

Acropora memiliki adaptasi yang tinggi terhadap lingkungan perairan juga memiliki keunggulan lain seperti memiliki pertumbuhan yang cepat dan cepat pulih apabila terjadi kerusakan (Edinger dan Risk, 2000). Bentuk umum kedua yang banyak ditemukan pada perairan Pulau Lirang adalah karang foliose (coral foliose) dan karang massive (coral massive), dimana

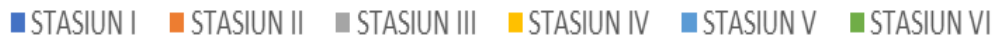

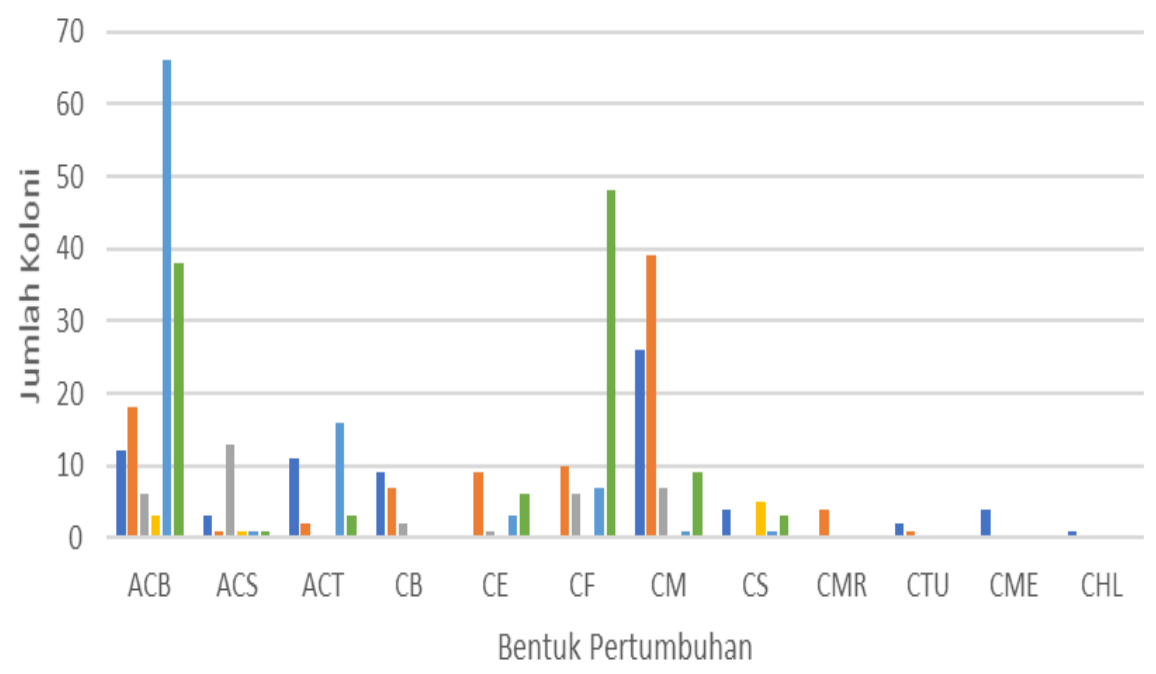

Gambar 4. Bentuk pertumbuhan karang keras (Scleractinian) di perairan Pulau Lirang dari semua stasiun penelitian 
keduanya memiliki ketahanan terhadap arus dan ombak yang besar, sedimentasi yang tinggi serta ketahanan terhadap kenaikan suhu pada perairan. Pada peristiwa bleaching tahun 1997/ 1998 berbagai karang massive seperti Leptastrea purpurea, Leptastrea transversa, Porites lutea dan terhindar atau mampu bertahan dari kenaikan suhu air laut dan tidak mengalami bleaching (Loya et al, 2001). Kekhasan dari Pulau Lirang adalah ditemukannya Tubipora musica yang pada penelitian ini hanya tercatat pada stasiun I dan II. Kelimpahan Tubipora musica ini sangat tinggi, dilihat dari pantai sebelah timur memiliki warna pasir kemerahan yang berasal dari pecahan atau fraksi dari koloni Tubipora musica.

\section{KESIMPULAN}

Persentase tutupan substrat rerata di Pulau Lirang termasuk golongan sedang (33,75\%) yang tersusun atas berbagai komposisi substrat seperti Acropora branching, coral foliose, coral massive, alga, dead coral, rubble dan sand. Semakin banyak jenis substrat dasar perairan maka akan semakin beragam komposisi ekosistem pada terumbu karang.

\section{DAFTAR PUSTAKA}

Ahmadia, G.N., Wilson J.R and Green A.L. 2013. Protocol Pemantauan Terumbu Karang Untuk Menilai Kawasan Konservasi Perairan, Coral Triangle Support Partnership, Bali.78 hlm.

Annas, R.A., Z.A. Muchlisin, M.A. Sarong. 2017. Short Communication: Coral reefs condition in Aceh Barat, Indonesia. Biodiversitas, 18(2): 524-529.

Arini, 2013. Potensi Terumbu Karang Indonesia. Tantangan dan Upaya Konservasinya. Info BPK Manado, 3(2): 147-173.

Birrell, C.L., McCook, L.J. and Willis, B.L., 2005. Effects of Algal Turfs and Sediment on Coral Settlement. Marine Pollution Bulletin, 51(1), pp.408-414.

Connell, J.H., Hughes, T.P. and Wallace, C.C., 1997. A 30 Year Study of Abundance, Recruitment, and Disturbance at Several Scales in Space and Time. Ecological Monographs, 67(4), pp.461-488.

Edinger, E.N. and Risk, M.J., 2000. Reef Classification by Coral Morphology Coral Reef Conservation Value. Biological Conservation, 92(1), pp.1-13.

English, S., Wilkinson, C., and Barker, V., 1994. Survey Manual for Tropical Marine Resources, Australian Institute of Marine Science, Townsville, 44-53 pp.

Estradivari, A. Damora, Amkieltiela, B. Subhan, B. Wibowo, C.N.N. Handayani, D. Daniel, F. Setiawan, H.M. Muda, H. Nanlohy, I. Dyahapsari, I.T. Hargiyatno, I. Pratiwi, I.C. Wardhana, K.T. Jan, N. Wisesa, V. Louhenapessy, G.N. Ahmadia, J.L. Harris, L. Glew, M. Provost, P. Mohebalian, B. Sumiono \& A. Kiklily. 2016. Kajian Ekologi, Sosial dan Pemanfaatan Sumber Daya Laut Kabupaten Maluku Barat Daya: Edisi Ringkasan. Jakarta, WWF.

FAO. 2000. Profile: The Republic of Indonesia. www.fao.org. Diakses pada [16/06/2016] pukul 12.15 wib.

Hill J, Wilkinson C. (2004). Methods for Ecological Monitoring of Coral Reefs. Townsville: Australian Institute of Marine Sciene.

Hillis-Colinvaux, L., 1980. Ecology and Taxonomy of Halimeda: Primary Producer of Coral Reefs. Advances in marine biology, 17, pp.1-327.

Inoue, S., Kayanne, H., Yamamoto, S. and Kurihara, H., 2013. Spatial Community Shift from Hard to Soft Corals in Acidified Water. Nature Climate Change, 3(7), pp.683-687.

Kuffner, I.B., Andersson, A.J., Jokiel, P.L., Ku'ulei, S.R. and Mackenzie, F.T., 2008. Decreased Abundance of Crustose Coralline Algae Due to Ocean Acidification. Nature Geoscience, 1(2), pp.114-117.

Langdon, C., Takahashi, T., Sweeney, C., Chipman, D., Goddard, J., Marubini, F., Aceves, H., Barnett, H. and Atkinson, M.J., 2000. Effect of Calcium Carbonate Saturation State on the Calcification Rate of An Experimental Coral Reef. Global Biogeochemical Cycles, 14(2), pp.639-654.

Loya, Y., Sakai, K., Yamazato, K., Nakano, Y., Sambali, H. and Van Woesik, R., 2001. Coral Bleaching: The Winners and The Losers. Ecology letters, 4(2), pp.122-131.) 
Nontji, A. 2007. Laut Nusantara. Penerbit Djambatan. Jakarta, $368 \mathrm{hlm}$.

Rasser, M. and Riegl, B., 2002. Holocene Coral Reef Rubble and Its Binding Agents. Coral Reefs, 21(1), pp.57-72.

Sammarco, P.W., Coll, J.C., La Barre, S. and Willis, B., 1983. Competitive Strategies of Soft Corals (Coelenterata: Octocorallia): Allelopathic Effects on Selected Scleractinian Corals. Coral Reefs, 1(3), pp.173-178.

Smith, J.E., Shaw, M., Edwards, R.A., Obura, D., Pantos, O., Sala, E., Sandin, S.A., Smriga, S., Hatay, M. and Rohwer, F.L., 2006. Indirect Effects of Algae on Coral: Algae Mediated, Microbe Induced Coral Mortality. Ecology letters, 9(7), pp.835-845.

Suharsono. 2008. Jenis-jenis karang di Indonesia. Lipi press. Jakarta, $344 \mathrm{hlm}$.

Tomascik, T., A.J. Mah, A. Nontji, and M.K. Moosa. 1997. The Ecology of the Indonesian Seas II. The Ecology of Indonesia series vol.VIII. Periplus Edition, Hongkong, 752 pp.

Zamani, P. N. 2006. Rehabilitasi terumbu harang: Teknik dan dasar penelitian. Biotrop, Bogor, 20$25 \mathrm{hlm}$. 